\title{
Seleção de indicadores de sustentabilidade em fragmentos florestais de Mata Atlântica na bacia hidrográfica do Rio Poxim-SE por meio do geoprocessamento
}

\author{
Selection indicators of sustainability in the Atlantic Forest fragments in basin hydrographic River Poxim through the \\ geoprocessing
}

\author{
Cristiano Cunha Costa', Laura Jane Gomes², Antônio Pacheco de Almeida ${ }^{3}$ \\ 1, 2, 3 Universidade Federal de Sergipe, São Cristóvão
}

\section{Resumo}

A degradação da mata atlântica brasileira resultou em um mosaico de fragmentos florestais, comprometendo os recursos naturais. A manutenção da cobertura florestal permite a manutenção do nível de água nos rios e da biodiversidade. Este trabalho objetivou a seleção de indicadores de sustentabilidade em fragmentos florestais de mata atlântica na bacia hidrográfica do rio Poxim por meio do geoprocessamento, visando subsidiar estratégias de recuperação e conservação desses fragmentos. Utilizou-se de aerofotografias correspondentes ao ano de 2004, tendo projeção UTM, Zona 24 Sul e Datum SAD-69. A seleção dos indicadores de sustentabilidade está relacionada ao uso e ocupação vetorizados através de ferramentas do Sistema de Informações Geográficas (SIG), neste caso o programa ARCGIS 9.2, permitindo identificar e quantificar indicadores de sustentabilidade ambiental na bacia hidrográfica do rio Poxim. Na bacia hidrográfica há apenas 01 reserva legal com 198,84 hectares, demonstrando o descumprimento do Código Florestal Brasileiro (1965). Do total de mata ciliar existente, menos da metade $(46,22 \%)$ está em conformidade com o Código Florestal Brasileiro. Os fragmentos florestais sofrem sérios impactos com agricultura da cana-de-açúcar e a pastagem. Com a seleção dos indicadores, é possível acompanhar e avaliar o comportamento desses indicadores, podendo-se afirmar se o agroecossistema é sustentável ao longo do tempo.

Palavras-chave: indicadores de sustentabilidade, sistema de informações geográficas, agroecossistemas.

\begin{abstract}
The Brazilian Atlantic forest degradation resulted in a mosaic of forest fragments, compromising natural resources. The maintenance of forest cover allows maintaining the level of water in rivers and biodiversity. This paper aims at the selection of sustainability indicators in forest fragments of Atlantic Forest in the river basin Poxim through geoprocessing, aiming to support recovery strategies and conservation of these fragments. We used to aerofotografias corresponding to the year 2004 and projection UTM, Zone 24 South Datum and DSS-69. The selection of sustainability indicators is related to the use and occupation vectorized through tools of Geographic Information System (GIS), in this case the program ARCGIS 9.2, allowing to identify and quantify environmental sustainability indicators in the river basin Poxim. In the basin there are only 01 reserve with 198.84 hectares, demonstrating the failure of the Brazilian Forest Code (1965). Of the total existing riparian forest, less than half $(46.22 \%)$ is in accordance with the Brazilian Forest Code. The forest fragments suffer serious impacts on agriculture of sugar cane and pasture. With the selection of indicators, it is possible to monitor and evaluate the behavior of these indicators, we can state that the agroecosystem is sustainable over time.
\end{abstract}

Keywords: sustainability indicators, geographic information system, agroecosystems. 


\section{INTRODUÇÃO}

O Brasil é, a nível mundial, um dos países de maior biodiversidade, haja vista que apresenta cerca de $10 \%$ dos organismos existentes no mundo e 30\% das florestas tropicais (MITTERMEIR et al., 1992).

A mata atlântica é um ecossistema degradado ao longo da história do país, por sua área de abrangência estar na faixa litorânea, desde o Rio Grande do Norte ao Rio Grande do Sul. Nessa faixa de terra, encontram-se os grandes centros urbanos, a maior densidade demográfica, e, consequentemente, foi onde se deu os principais ciclos econômicos que moveram a economia do Brasil, ao longo da sua história.

No entanto, embora protegido por leis ambientais específicas, atualmente, restam de $7 \%$ da superfície originalmente coberta por Mata Atlântica, sendo que das 633 espécies de animais ameaçadas de extinção no Brasil, 383 ocorrem nesse bioma (SOS MATA ATLÂNTICA, 2009). Nesse sentido, a mata atlântica se apresenta como um mosaico composto por fragmentos florestais de diversos tamanhos e em diferentes estágios de degradação (GUATURA et al, 1996; ZAÚ, 1998).

O desenvolvimento da pecuária e a expansão da fronteira agrícola foram os principais motivos que promoveram o desmatamento das grandes coberturas florestais de mata atlântica para a implantação dessas atividades. Dessa forma, o ser humano é responsável pelas mudanças ambientais que estão ocorrendo atualmente e pela perda da biodiversidade, devido ao seu inadequado comportamento, colocando em risco a sustentabilidade econômica, social e ambiental.

Depois da $2^{\text {a }}$ Conferência das Nações Unidas sobre Meio Ambiente e Desenvolvimento (ECO92) foi reconhecido que o crescimento e desenvolvimento econômicos alteram os sistemas naturais, embora não se possam pôr em risco os sistemas naturais mais importantes como atmosfera, água, solos e seres vivos (HANSEN, 2001). Assim, como resultado desse encontro houve a elaboração da agenda 21 brasileira, que propõe a elaboração de parâmetros de indicadores para a adoção do desenvolvimento sustentável.

Segundo Iamamoto (2005) diante das práticas do desenvolvimento sustentável, o agroecossistema vem sendo tratado como uma maior complexidade das soluções alternativas no ecossistema como um todo. Dessa forma, para Nazario (2003) a natureza deixa de ser encarada apenas como provedora de recursos a serviço do homem, passando a ser entendida, também, como um sistema vivo que dá suporte aos processos produtivos.

É importante salientar que deve haver um equilíbrio entre as três dimensões para que haja desenvolvimento sustentável. Dessa maneira, surge a necessidade de elaborar/buscar indicadores para mensurar o grau de sustentabilidade de um local, região ou sistema.

Indicadores são medidas compostas de variáveis, ou seja, medições baseadas em mais de um dado. Um índice é construído através do somatório de resultados de atributos individuais (LOURENÇO, 2001).

Para Marques et al. (2004), a avaliação da sustentabilidade nas dimensões ecológica, econômica e social requer o estabelecimento de índices em cada uma dessas dimensões, como também suas inter-relações.

Um aspecto determinante é a impossibilidade de determinar a sustentabilidade de um sistema considerando apenas um indicador, ou indicadores que se refiram a apenas um aspecto do sistema. A sustentabilidade é determinada por um conjunto de fatores (econômicos, sociais, ambientais, entre outros) que devem ser contemplados (MARZALL \& ALMEIDA, 2000).

Ao selecionar indicadores, deve-se atentar para o fato de que os mesmos devem apontar para a ocorrência de perturbações no sistema e, também, atentar para a potencialidade de perturbações futuras. No entendimento de Marques et al. (2004) essa perspectiva futura deve ser obtida por meio da adoção de um conceito de pensamento sistêmico, pois deve contemplar os componentes mais significativos do agroecossistema estudado.

Nesse sentido, torna-se necessário a adoção de metodologia para a seleção de indicadores de sustentabilidade para o sistema, como ferramenta para estratégias de conservação de recuperação da floresta degradada.

O objetivo deste trabalho foi estabelecer indicadores para avaliação da sustentabilidade dos fragmentos de mata atlântica em propriedades rurais na bacia hidrográfica do rio Poxim, visando subsidiar o planejamento de estratégias de recuperação e conservação desses fragmentos. 


\section{METODOLOGIA}

\section{I CaracterizaÇão da ÁreA de ESTUdo}

O estado de Sergipe é banhado por seis bacias hidrográficas: rio São Francisco, rio Japaratuba, rio Sergipe, rio Vaza-Barris, rio Piauí e rio Real. A bacia hidrográfica do rio Sergipe é a mais importante para o Estado e possui área correspondente a $14,9 \%$ do total da área estadual. Esta unidade de planejamento apresenta uma série de bacias hidrográficas, destacando-se a do Poxim a qual é considerada a mais importante do Estado por ter no curso final do rio a capital Aracaju (BRASIL, 2001; SERGIPE, 2004). É formada pelos rios principais: Poxim-Mirim, Poxim-Açu e Pitanga.

A bacia hidrográfica do rio Poxim compreende uma área de $397,95 \mathrm{~km}^{2}$ aproximadamente. De formato alongado, no sentido Noroeste/Sudeste, esta unidade de planejamento está limitada ao Sul pela bacia hidrográfica do rio Vaza-Barris e, ao Norte, pelo rio Sergipe. As principais nascentes se localizam a oeste, limite final da Serra dos Cajueiros e sua foz a Leste no complexo estuarino Sergipe/ maré do Apicum, próximo ao Oceano Atlântico (FÉLIX \& SILVA, 2007).

A bacia hidrográfica do rio Poxim está situada entre as coordenadas geográficas de $10^{\circ} 55^{\prime} 00^{\prime \prime}$ e $10^{\circ} 45^{\prime} 00^{\prime \prime}$ de latitude Sul e $37^{\circ} 05^{\prime} 00^{\prime \prime}$ e $37^{\circ} 22^{\prime} 00^{\prime \prime}$ de longitude Oeste, abrange os municípios de Itaporanga D’Ajuda, Areia Branca, Laranjeiras, Nossa Senhora do Socorro, São Cristóvão e Aracaju (figura 1).

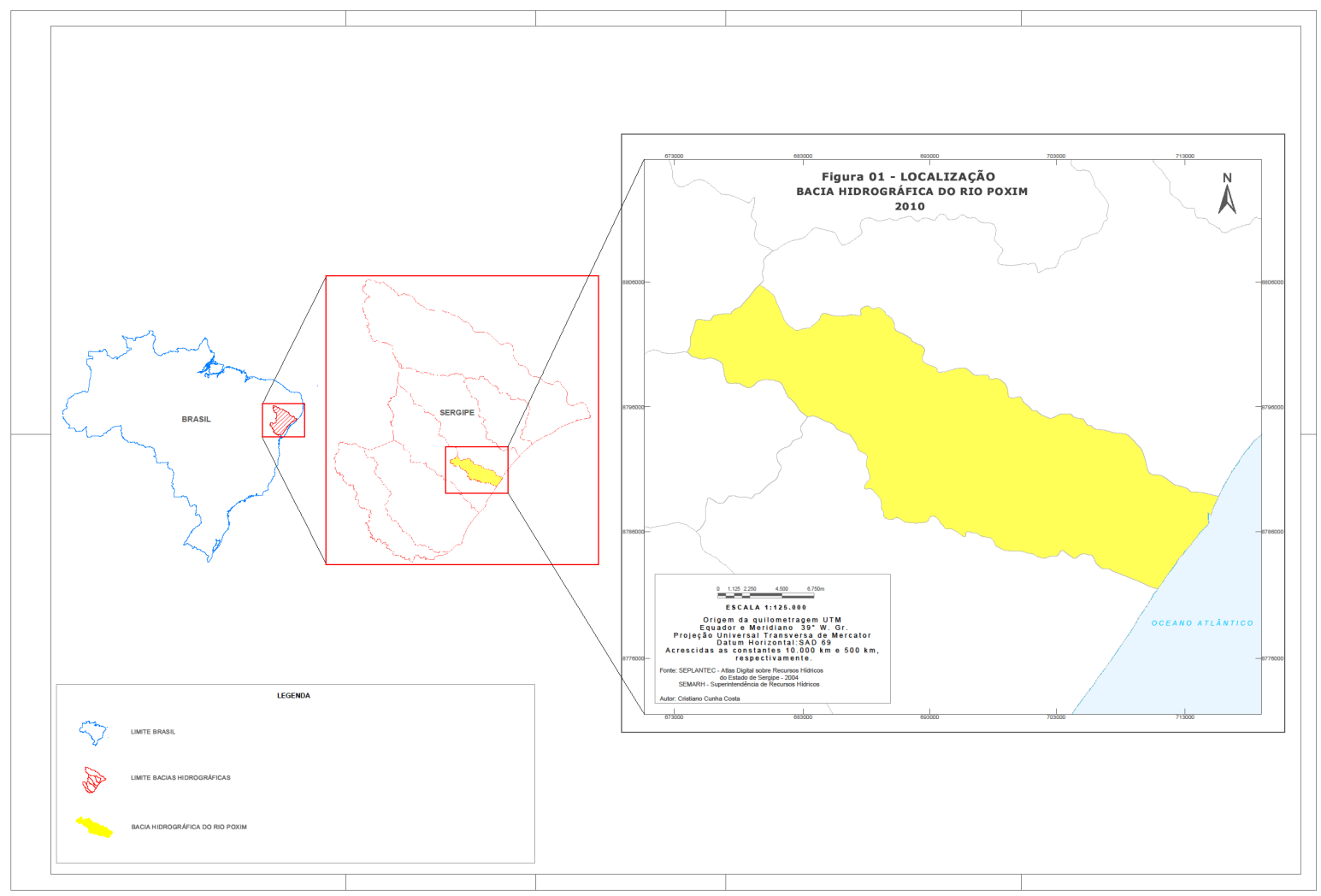

Figura 01. Localização da bacia hidrográfica do rio Poxim.

A região está localizada na Zona Costeira de Sergipe, sobre a bacia sedimentar Sergipe/Alagoas, onde predominam planícies típicas dos tabuleiros areno-argilosos. A vegetação nativa predominante, inserida no bioma da Mata Atlântica, atualmente se encontra restrita aos manguezais nos estuários, vegetação de restinga sobre os terrenos arenosos e alguns remanescentes da Floresta Tropical Úmida (BRASIL, 2001). 


\subsection{ColetA DAS INFORMAÇÕES}

Para a realização do estudo, utilizou-se de fotografias aéreas georeferenciadas cedidas pela Superintendência de Recursos Hídricos de Sergipe (SRH) da Secretaria de Meio Ambiente e Recursos Hídricos (SEMARH), correspondendo à faixa litorânea do estado de Sergipe no ano de 2004, tendo projeção UTM, Zona 24 Sul e Datum SAD-69. São fotografias ortoretificadas e ortogeoreferenciadas na escala 1:10.000.

\subsection{SeleÇão dos INDICADORES DE SUSTENTABILIDADE}

A seleção dos indicadores de sustentabilidade estão relacionados ao uso e ocupação da bacia hidrográfica do rio Poxim, vetorizados através de ferramentas do Sistema de Informações Geográficas (SIG), neste caso o programa ARCGIS 9.2, permitindo identificar e quantificar indicadores de sustentabilidade ambiental na bacia hidrográfica do rio Poxim.

\subsection{I Área de Reserva Legal}

O indicador Área de Reserva Legal permite mensurar a quantidade de vegetação obrigatória e a existente no interior das propriedades rurais que pertencem a bacia do rio Poxim segundo o que estipula o Código Florestal Brasileiro que no caso da mata atlântica é de $20 \%$.

Neste caso, a estimativa da quantidade de reserva legal se deu de acordo com o tamanho das propriedades rurais pertencentes aos municípios que compõem a bacia em estudo.

\subsection{2 Área de Mata Ciliar}

O Código Florestal Brasileiro (1965) relata que áreas de preservação permanente tem como função ambiental de preservar os recursos hídricos, a paisagem, a estabilidade geológica, a biodiversidade, o fluxo gênico de fauna e flora, proteger o solo e assegurar o bem-estar das populações humanas.

No caso das matas ciliares corresponde a vegetação existente nos cursos dos rios, favorecendo a estabilidade das margens dos rios e a proteção da biodiversidade. Por outro lado, a retirada a vegetação ciliar implica na erosão de terra, com conseqüente assoreamento dos rios, redução da quantidade e qualidade da água, redução da fauna aquática.

O indicador Área de Preservação Permanente permite medir a área de mata ciliar atual e a área necessária em torno das nascentes e no curso dos rios de acordo com o Código Florestal Brasileiro (1965). Desse modo, permite medir a área de mata ciliar existente e a área de mata ciliar necessária ao longo do curso dos rios, de acordo com a largura mínima determinado pela legislação.

O levantamento da mata ciliar foi feito pela Superintendência de Recursos Hídricos (SRH) por meio da interpretação de fotografias aéreas as quais foram digitalizadas no programa ARCGIS 9.2, na escala de visualização de 1:10.000.

Para estimar a quantidade de mata ciliar necessária na bacia, aplicou-se um buffer de $30 \mathrm{~m}$ para toda a bacia hidrográfica do rio Poxim, possibilitando estimar quanto de mata existe na área de estudo e quanto precisa ser restaurada para atender as exigências legais.

\subsubsection{Cobertura Florestal}

Este indicador possibilita mensurar o percentual de cobertura florestal necessária e a existente na bacia hidrográfica do rio Poxim, sendo que no bioma Mata Atlântica deve ser de $20 \%$ conforme pregoa o Código Florestal Brasileiro.

A digitalização dos fragmentos de mata atlântica foi por meio de fotografias aéreas as quais foram digitalizadas no programa ARCGIS 9.2, na escala de visualização de 1:10.000.

\section{RESULTADOS E DISCUSSÃO}

\subsection{AplicaÇÃo dos indicAdores de sustentabilidade}

\subsection{Reserva Legal}

Segundo o Código Florestal Brasileiro, instituído pela Lei 4771/65, determina que a área de reserva legal corresponde a aquela localizada no interior de uma propriedade ou posse rural, excetuada 
a de preservação permanente, sendo que se deve deixar uma área de $20 \%$ para a reserva legal da área correspondente da área da propriedade. Dessa forma, há uma intrínseca relação entre o tamanho da propriedade rural e a área que deve ser destinada a reserva legal no interior do imóvel rural.

Com relação a quantidade de propriedades rurais, observou-se que há 4.597 pequenas propriedades, as médias propriedades somam um total de 794, seguidas das grandes que somam 150 propriedades. Dessa forma, há um total de 5.541 propriedades rurais nos municípios que compõem a bacia hidrográfica do rio Poxim (tabela 01$)$.

Tabela 01. Quantidade de propriedades, somatório das áreas e da reserva legal necessária, em hectares, da bacia do rio Poxim-SE.

\begin{tabular}{|c|c|c|c|}
\hline $\begin{array}{l}\text { Trmanthode } \\
\text { propriedade }\end{array}$ & $\begin{array}{l}\text { Edas } \\
\text { propriadades }\end{array}$ & Eda ́́fer (ha) & $\begin{array}{l}\text { E de neserva legal } \\
\text { (he) }\end{array}$ \\
\hline Pequera propriedfade & 4597 & $26.839,21$ & 5367,84 \\
\hline Módia propriedade & 794 & 26915,26 & 5373,05 \\
\hline Grande propriodade & 150 & $61.141,21$ & 12224,24 \\
\hline Total & 5541 & 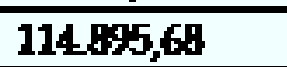 & $22 \% 7,13$ \\
\hline
\end{tabular}

Fonte: INCRA, 2010; Pesquisa, 2010.

É possível notar que à medida que aumenta o tamanho das propriedades; há uma redução na sua quantidade, sendo que quanto ao somatório das áreas de acordo com as categorias de tamanho, é inversamente proporcional ao tamanho das propriedades, em hectares. Desse modo, a área total das grandes propriedades $(61.141,21 \mathrm{ha})$ é superior ao somatório das áreas das pequenas propriedades $(26.839,21 \mathrm{ha})$ juntamente com as áreas das médias propriedades $(26.915,26 \mathrm{ha})$.

Com relação a áreas de reserva legal, verificou-se que, pela classificação de tamanho as pequenas propriedades deveriam ter uma área de reserva legal de 5.367,84 hectares, seguido das médias propriedades que deveriam ter uma área de reserva legal de 5.383,05 hectares e 12.228, 24 hectares de área de reserva legal para as grandes propriedades. Os municípios que compõem a bacia hidrográfica do rio Poxim deveriam ter uma área de reserva legal total de 22.979,13 hectares, garantindo os benefícios ambientais diretos (aumento da qualidade e da quantidade de água, extração de produtos florestais, dentre outros) e indiretos (melhoria da qualidade do ar, conforto térmico, manutenção da biodiversidade, entre outros).

Na pequena propriedade, a manutenção ou a compensação da reserva legal podem ser levados em consideração os plantios de árvores frutíferas, ornamentais ou industriais, compostos por espécies exóticas. Além disso, a averbação da reserva legal para esse tipo de propriedade é gratuita.

No estado de Sergipe, o Código Florestal não está sendo levado em consideração, ou seja, não está havendo um cumprimento do que determina a lei ambiental em vigor.

Tabela 02. Quantidade de reserva legal no estado e na bacia do rio Poxim e suas respectivas áreas averbadas, 2010.

\begin{tabular}{|c|c|c|c|c|}
\hline An: & N=RI (estado) & ERI no estedo (ha) & NoRLma baia & L RLna baria (ha) \\
\hline 2004 & 13 & 56216 & $\overline{-}$ & - \\
\hline 2005 & 41 & $5.121,64$ & $\mathbf{n}$ & 198,84 \\
\hline 2006 & 31 & 4633,38 & - & - \\
\hline 2007 & 14 & 1938,70 & - & - \\
\hline 2008 & 17 & $4 \mathbf{7 9}, 47$ & - & - \\
\hline 2009 & 73 & 272,88 & - & - \\
\hline 2010 & & & & - \\
\hline
\end{tabular}

Fonte: IBAMA, 2010; ADEMA, 2010. 
Do ano de 2004 até o ano de 2010, pouco se tem averbado área de reserva legal no estado de Sergipe, mais especificamente na bacia do rio Poxim (tabela 02). Observou-se que o ano de 2005, houve a maior quantidade de área averbada de reserva legal no estado sergipano (5.121,64 hectares), seguido pelo ano de 2006 (4.633,38 hectares) e pelo ano de 2009 (2.722,88 hectares). Entretanto, o ano de 2008 apresentou a menor quantidade de área averbada em reserva legal (429,47 hectares).

Com relação ao número de reservas legais averbadas no estado, observou-se que 2009 foi o ano em que mais se averbou reserva legal no estado (73 reservas legais), seguido de 2005 (41 reservas legais) e 2006 (31 reservas legais). O ano de 2005 embora tivesse 41 averbações, o somatório das áreas averbadas é de 5.121,64 hectares. Isso se deve ao tamanho das propriedades rurais (pequenas, médias ou grandes propriedades), uma vez que a área de reserva legal que deve ser averbada deve corresponder a $20 \%$ da área total da propriedade.

Quando se refere à bacia hidrográfica do rio Poxim, verifica-se que houve averbação de reserva legal apenas no ano de 2005, correspondendo a somente uma área de reserva legal com área de 198,84 hectares, localizada no município de São Cristóvão.

Por outro lado, no ano de 2006 o dono de uma propriedade rural deu entrada no processo de averbação de reserva legal, porém a reserva legal da propriedade não existe oficialmente até então, pois o proprietário não a averbou em cartório.

Pelo Código Florestal Brasileiro (1965), a averbação da reserva legal em cartório garante ao proprietário da terra benefícios como isenção do Imposto Territorial Rural (ITR) (ANGHER, 2008).

Além disso, a permanência da reserva legal permite a conservação da biodiversidade, uso sustentável dos recursos naturais, manutenção do solo e aumento da quantidade de água na bacia.

\subsection{2 Área de Mata Ciliar}

A bacia do rio Poxim tem uma rede de drenagem total de 568,02 km, sendo que apenas 43,78 $\mathrm{km}$ é coberta por mata ciliar (figura 02). Dessa forma, evidencia-se o descumprimento da legislação referente à preservação de áreas de preservação permanente, neste caso, as áreas de mata ciliar.

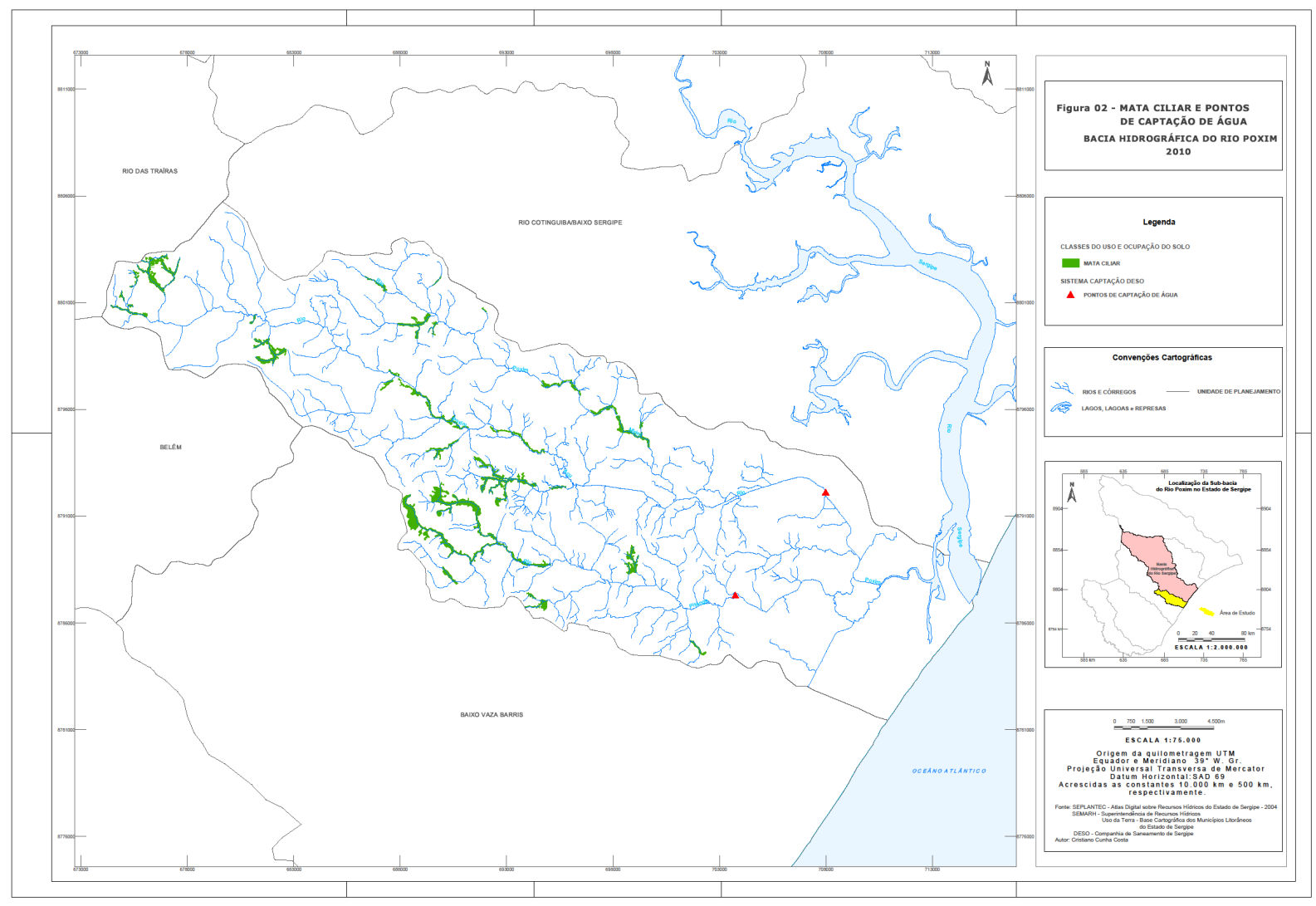

Figura 02. Mata ciliar e pontos de captação de água na bacia hidrográfica do rio Poxim-SE. 
Segundo a DESO Companhia de Saneamento de Sergipe, a bacia hidrográfica do rio Poxim contribui significativamente no abastecimento público, uma vez que $40 \%$ do total de água consumida pela capital Aracaju vem dessa bacia, mais especificamente $25 \%$ do rio Poxim, $6 \%$ do rio Pitanga e 9\% é oriundo da água subterrânea, sendo que o restante é retirado do rio São Francisco e pelo aqüífero cárstico do ibura (Sergipe, 2010).

Com a degradação da mata ciliar, está havendo uma redução na qualidade e na quantidade de água na bacia do Poxim, afetando na demanda de água para o abastecimento. Para Silva et al. (2004) a contribuição do rio Poxim para o abastecimento da capital sergipana já foi de $70 \%$ e a tendência é que haja uma diminuição ainda mais deste percentual.

Em se tratando em conservação de mata ciliar no estado de Sergipe, observa-se que há uma densa malha de rios, formada por rios de pequeno porte, destacando-se a bacia do rio Poxim o qual apresenta relevante importância para o abastecimento humano (FERREIRA et al., 2006).

A confecção do buffer permitiu observar que, considerando a largura mínima de mata ciliar recomendado pelo Código Florestal, a bacia deveria possuir uma área de mata ciliar de $34,46 \mathrm{~km}^{2}$. No entanto, $31,22 \mathrm{Km}^{2}$ da bacia do rio Poxim não possui área de preservação permanente do tipo mata ciliar em conformidade com a legislação.

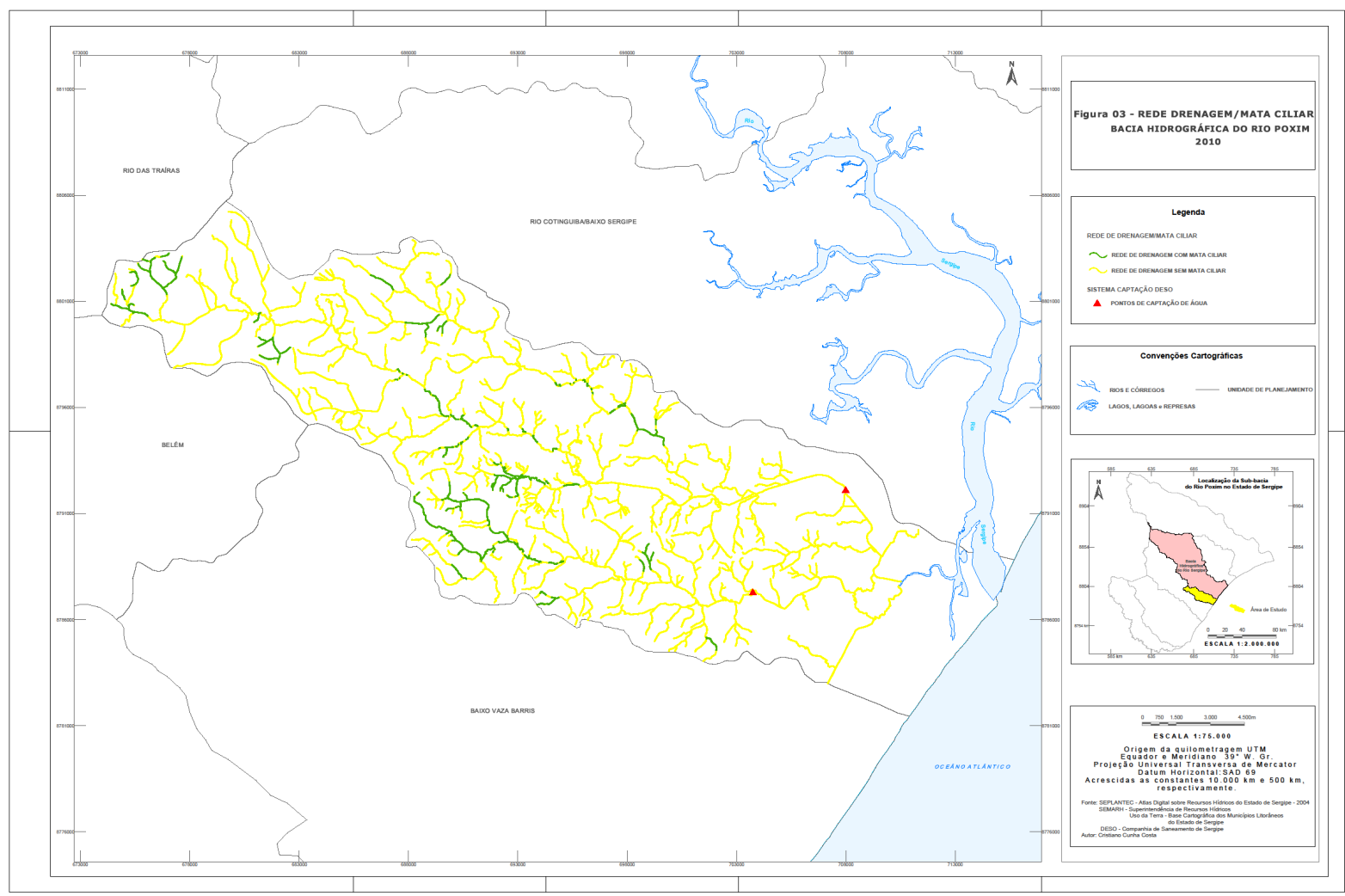

Figura 03. Rede de drenagem e mata ciliar na bacia hidrográfica do rio Poxim-SE.

No entendimento de Aguiar Netto (2006), a manutenção da mata ciliar requer um repensar no processo de gestão dos recursos hídricos, dentro do contexto que englobe novas práticas de usos desses ecossistemas baseadas nas diferentes formas de apropriação e dos diferentes níveis de suporte da relação homem-natureza.

Nesse contexto, observou-se que bacia hidrográfica do rio Poxim, pertencente à bacia hidrográfica do rio Sergipe, deveria ter uma área de $31,22 \mathrm{~km}^{2}$ de mata ciliar, conforme pregoa o Código Florestal, sancionada pela Lei Federal 4771/65, abrangendo os 30 metros para leito dos cursos de rios de até 10 metros de largura (tabela 03). 
Tabela 03. Quantidade necessária e existente de mata ciliar na bacia hidrográfica do rio Poxim-SE, em 2004.

\begin{tabular}{lll}
\hline Mata ciliar & Área $\left(\mathrm{km}^{2}\right)$ & Área $(\%)$ \\
\hline Existente & 3,24 & 9,24 \\
\hline Necessária & 31,22 & 100 \\
\hline
\end{tabular}

Fonte: Pesquisa, 2010.

No entanto, diante do desrespeito da legislação ambiental, com a supressão da mata ciliar, na bacia do rio Poxim existe somente $3,24 \mathrm{~km}^{2}$ desse tipo de área de preservação permanente, que representa $9,24 \%$ da área total da bacia. Tal fato de deve, principalmente, a retirada da mata ciliar para a prática de atividades agropastoris, não se preocupando com os impactos negativos da ação antrópica: alargamento do leito dos rios, assoreamento dos cursos d'água, redução da quantidade e qualidade da água, redução da fauna aquática e implicações econômicas para as populações ribeirinhas.

Por meio do buffer, do total recomendado de mata ciliar apenas $46,22 \%$ está em conformidade com o Código Florestal e 34,38\% está em desacordo com a legislação (figura 04). Dessa maneira, é constatada a situação irregular das áreas de preservação permanente do tipo mata ciliar diante da lei em vigor, uma vez que não é respeitado o mínimo estipulado pela legislação para a preservação dessas áreas de preservação permanente.

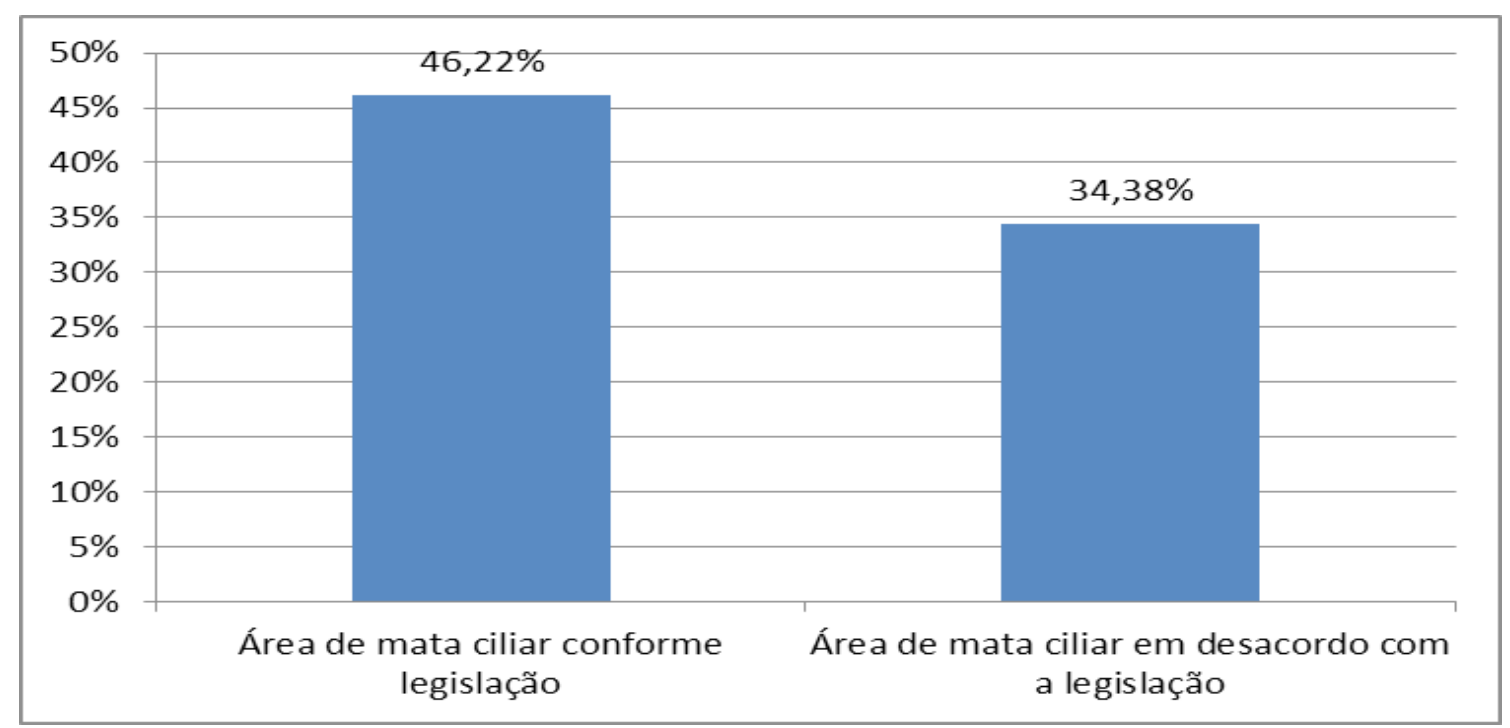

Figura 04. Área de mata ciliar conforme elaboração do buffer de acordo com o Código Florestal (1965), bacia do rio Poxim-SE.

Vale ressaltar que 19,40 \% correspondem à área de mata ciliar que está acima de 30 metros, que é o tamanho mínimo de mata ciliar levado em consideração na elaboração do buffer.

Nesse contexto, justificam-se os estudos fitossociológicos aliados a estudos hidrográficos na unidade de planejamento da bacia hidrográfica do rio Poxim, diante da supressão das matas ciliares, no sentido de recuperar as áreas degradadas (FERREIRA et al., 2006). Desse modo, torna-se necessário o estabelecimento de ações de monitoramento e recuperação das matas ciliares, no sentido de promover a conservação dos recursos naturais.

As matas ciliares, segundo o Código Florestal Brasileiro (1965), são consideradas áreas de preservação permanente, sendo que se deve manter uma faixa de mata ciliar de acordo com a largura do corpo d'água. Dessa forma, para rios com menos de 10 metros de largura, deve-se preservar 30 metros de vegetação ciliar. 


\subsubsection{Cobertura florestal}

De acordo com o levantamento do uso e ocupação do solo foi possível ter uma estimativa da quantidade de mata atlântica existente na bacia hidrográfica do rio Poxim. Desse modo, observou-se que a bacia possui uma área de $84,87 \mathrm{~km}^{2}$ coberta por vegetação de mata atlântica, correspondendo a $21,24 \%$ da área total da bacia (tabela 04 ).

Tabela 04. Situação da cobertura florestal na bacia hidrográfica do rio Poxim no ano de 2004.

\begin{tabular}{lll}
\hline Cobertura florestal & Área $\left(\mathrm{km}^{2}\right)$ & Área (\%) \\
\hline Necessária & 79,59 & 20 \\
Existente & 84,87 & 21,24 \\
\hline
\end{tabular}

Fonte: Pesquisa, 2010.

O desmatamento florestal se deu por conta do processo histórico de uso e ocupação do estado de Sergipe e, neste caso, mais especificamente, a bacia do Poxim, por conta do crescimento urbano e a exploração de atividades agropecuárias, resultando em fragmentos florestais de mata atlântica de diferentes tamanhos e estágios de degradação.

A retirada da vegetação para o cultivo e o desenvolvimento de atividades pastoris sem a adoção de práticas preservacionistas e conservacionistas resultam em impactos negativos ao meio ambiente, como a perda da biodiversidade, e a alteração da paisagem natural no território sergipano.

A cobertura florestal do solo por vegetação está relacionada com:

Manutenção da biodiversidade, propiciando uma diversidade genética das espécies de fauna e flora, como também a manutenção dos recursos naturais, no sentido de proporcionar benefícios diretos, através do manejo racional da biodiversidade, e indiretos, como a melhoria da qualidade do ar, conforto térmico, melhor qualidade e quantidade de recursos hídricos, dentre outros.

Infiltração da água, uma vez que as raízes permitem que a água da chuva penetre no solo, abastecendo o lençol freático e, consequentemente, aumentar o fluxo de vazão de água nas nascentes e aumentar a quantidade e a qualidade da água nos rios.

Manutenção do solo, haja vista que a retirada da cobertura florestal deixa o solo exposto e suscetível a ação dos ventos e do impacto da chuva, favorecendo o processo de erosão, removendo partículas de solo para o leito dos rios, provocando assoreamento e reduzindo a qualidade e quantidade do recurso hídrico.

Embora a quantidade de área estimada para a cobertura florestal esteja acima do que determina a legislação ambiental vigente, há a preocupação com relação a sustentabilidade dos fragmentos, uma vez que $92,71 \%$ dos fragmentos florestais existentes na bacia do Poxim possuem tamanho médio de 18,58 hectares, sendo que o maior fragmento tem uma área de 2347,55 hectares.

Além disso, a fragmentação está sendo intensificada com a existência de torres de transmissão elétrica, voçorocas, retirada de madeira e existência de lixo doméstico deixado por populações do entorno desses fragmentos, tornando-se os principais fatores que agravam o processo de fragmentação na bacia do rio Poxim.

Nesse contexto, manutenção das áreas de cobertura florestal, além de ser ponto crucial para a conservação, planejamento e gestão dos recursos hídricos, é importante na adoção de estratégias de conservação, uma vez que permite a existência da biodiversidade, o fluxo gênico entre os fragmentos seja por meio do deslocamento de fauna ou pela dispersão de sementes.

\section{CONSIDERAÇÕES FINAIS}

Com relação a averbação de reserva legal no estado, conclui-se que de do total de 89 reservas legais averbadas no período de 2004 até 2010, apenas 01 foi averbada na bacia hidrográfica do rio Poxim.

Segundo o levantamento, do total de mata ciliar existente, menos da metade $(46,22 \%)$ está em conformidade com o Código Florestal Brasileiro (1965) que estipula uma largura mínima de 30 metros 
de mata ciliar; $34,38 \%$ desse tipo de área de preservação permanente estão em desacordo com a legislação. Entretanto, apenas 19,40 \% correspondem à área de mata ciliar que está acima de 30 metros, ou seja, de acordo com a legislação, que é o tamanho mínimo de mata ciliar levado em consideração na elaboração do buffer.

Os fragmentos florestais sofrem sérios impactos com relação às atividades desenvolvidas no seu entorno. Além disso, a fragmentação está sendo intensificada com a existência de torres de transmissão elétrica, voçorocas, retirada de madeira e existência de lixo doméstico deixado por populações do entorno desses fragmentos, tornando-se os principais fatores que agravam o processo de fragmentação na bacia hidrográfica do rio Poxim.

Com a seleção dos indicadores, é possível acompanhar e avaliar o comportamento desses indicadores, podendo-se afirmar se o agroecossistema é sustentável ao longo do tempo. Nesse sentido, pode-se intervir no agroecossistema em estudo, de forma a estabelecer critérios para o desenvolvimento de projetos de conservação e preservação dos fragmentos florestais, estabelecendo mecanismos de planejamento e monitoramento baseados em parâmetros de sustentabilidade.

\section{BIBLIOGRAFIA}

AGUIAR NETTO, A. O.; COSTA, A. M.; MACEDO, L. C. Características fisiográficas e ambientais. In: ALVES, J. do P. H.; GARCIA, C. A. B.; AGUIAR NETTO, A. O. de; FERREIRA, R. A. (Coords.) Diagnóstico e avaliação da sub-bacia Hidrográfica do rio Poxim. Relatório de Pesquisa. Sergipe: EDUFS/FAPESE, p. 101-136, 2006. 245p.

ANGHER, A. J. Vade Mecum Acadêmico de Direito. 6. Ed. - São Paulo: Rideel, 2008, 1838p.

BRASIL / Agência Nacional das Águas. A gestão dos recursos hídricos no Estado de Sergipe. Série: Sistema nacional de informações sobre recursos hídricos, CD Nº 1, versão preliminar, 2001.

FÉLIX, F. F.; SILVA, M. G. Aspecto sócio ambiental da bacia hidrográfica do rio Poxim: percepção ambiental do Povoado do Parque dos Farois-SE. In: Périódicos do Fórum Ambiental da Alta Paulista. V. III, 2007.

FERREIRA, R. A.; SANTOS, T. I. S.; SANTOS, B. L. Análise florística e fitossociológica em nascentes e fragmentos de vegetação do rio Poxim. In: ALVES, J. do P. H.; GARCIA, C. A. B.; AGUIAR NETTO, A. O. de; FERREIRA, R. A. (Coords.) Diagnóstico e avaliação da sub-bacia Hidrográfica do rio Poxim. Relatório de Pesquisa. Sergipe: EDUFS/FAPESE, p. 137-162, 2006.

GUATURA, I. N.; CORREAA, F.; COSTA, J. P. O.; AZEVEDO, P. U. E. A questão fundiária: roteiro para a solução dos problemas fundiários nas áreas protegidas da Mata Atlântica. Roteiro para a conservação de sua biodiversidade. Série Cadernos da Reserva da Biosfera, Caderno 1, 1996. 47 p.

HANSEN, M. A. F. Proposta e indicadores de sustentabilidade visando à síntese do diagnóstico ambiental, social e econômico para Bacias Hidrográficas. Tese de doutorado. Programa de Pós-graduação em Engenharia e Recursos hídricos e Saneamento Ambiental. Universidade Federal do Rio Grande do Sul, 2001.

IAMAMOTO. A. T. V. Agroecologia e Desenvolvimento Rural. Dissertação de Mestrado. Escola Superior de Agricultura "Luiz de Queiroz". Universidade de São Paulo. Piracicaba, 2005. 79p.

LOURENÇO, M. S. Questões Técnicas na Elaboração de Indicadores de Sustentabilidade. Texto disponível em: http://www.unifae.br/publicacoes/pdf/sustentabilidade/marcus lorenco.pdf. Acesso em: 01/05/09.

MARQUES, O.; TIENNE, L.; CORTINES, E.; VALCARCEL, R. Atributos ambientais definidores de presença de fragmentos florestais de mata atlântica em microbacias instáveis. Revista Universidade Rural: Série Ciências da Vida, Seropédica. RJ: EDUR, v. 24, n.2, jul.-dez., 2004. p. 145-150 
MARZALL, K.; ALMEIDA, J. Indicadores de Sustentabilidade para Agroecossistemas: Estado da arte, limites e potencialidades de uma nova ferramenta para avaliar o desenvolvimento sustentável. Cadernos de Ciência \& Tecnologia, Brasília, v.17, n.1, p.41-59, jan./abr. 2000.

MITTERMEIR, R. A.; WERNER, T.; AIRES, J. M.; FONSECA, G. A. B. O país da megadiversidade. Revista Ciência Hoje. v. 14, n. 81, 1992. p. 20-27.

NAZARIO, N. atitudes de produtores rurais: perspectivas de conservação dos fragmentos de cerrado do Assentamento Reunidas, Promissão, São Paulo. Dissertação de Mestrado Instituto de Biociências. Universidade de São Paulo. São Paulo, 2003. 94p.

SERGIPE - Secretaria de Estado do Planejamento, da Ciência e da Tecnologia. Atlas digital sobre recursos hídricos Sergipe. SEPLANTEC/SRH. Sergipe, 2004.

SILVA, A. S.; BUSCHINELLI, C. C. A.; RODRIGUES, I. A.; MACHADO, R. E. Índice de sustentabilidade ambiental do uso da água (ISA_ÁGUA): municípios da região do entorno do rio Poxim, SE. Boletim de Pesquisa e Desenvolvimento. Jaguariúna: Embrapa Meio Ambiente, 2004. 46 p.

FUNDAÇÃO SOS MATA ATLÂNTICA. Atlas dos remanescentes florestais da Mata Atlântica. Relatório Parcial (2005-2008). Fundação SOS Mata Atlântica/INPE. São Paulo, 2009. 156p.

ZAÚ, A. S. Fragmentação da mata atlântica: aspectos teóricos. Revista Floresta e Ambiente. v. 5, n. 1, 1998. p. $160-170$. 